\title{
Infectious Agents in Coronary Atherosclerosis
}

\author{
Luís Beck da Silva Neto, Jorge Pinto Ribeiro
}

Porto Alegre, RS

In 1908, Sir William Osler was the first to suggest that infection might play a role in the pathogenesis of atherosclerosis ${ }^{1}$. Even though this view was not widely accepted originally, a renewed interest currently abounds regarding the contribution of infection to the pathogenesis and progression of ischemic heart disease. The current concept of atherosclerosis is based on the model "response to injury" proposed by Ross in $1986^{2}$. This model suggests that infection may contribute to the formation of atherosclerosis through injury to the vascular endothelium along with inflammatory, metabolic and hemostatic mechanisms ${ }^{2}$. In the 70 s, formation of atherosclerotic lesions in the arteries of chickens infected with herpes virus was demonstrated experimentally ${ }^{3}$. The recent discovery of Helicobacter pylori, as an etiological agent of another chronic disease, peptic ulcer, suggests that an infectious etiology for atherosclerosis should be considered ${ }^{4}$. Since then, associations between ischemic heart disease and some Gram-negative bacteria, such as Helicobacter pylori and Chlamydia pneumoniae, and certain herpes viruses, especially cytomegalovirus ${ }^{5}$, have been reported. Most of the published material consists of epidemiological studies based on associations between the serology of the respective antibodies and ischemic heart disease or on immunohistochemical evidence of the presence of bacteria or viruses in atherosclerotic lesions. Recently, new evidence originating from controlled clinical trials has emphasized this new paradigm for managing ischemic heart disease ${ }^{6}$. This study aims to provide an updated review of the evidence available relating infection to coronary atherosclerosis.

\section{Serum-epidemiological studies}

Chlamydia pneumoniae - In 1988, a Finnish case control study showed that, after an acute myocardial infarction, most patients (68\%) developed significant seroconversion against a specific epitope of Chlamydia pneumoniae, while this happened only in $3 \%$ of the control patients and in none of those patients with chronic coronary heart disease ${ }^{7}$. In addition, anti-Chlamydia $\mathrm{IgG}$ and

Hospital de Clínicas de Porto Alegre e Faculdade de Medicina da UFRGS. Mailing address: Jorge Pinto Ribeiro - Serviço de Cardiologia - Hospital de Clínicas de Porto Alegre - Rua Ramiro Barcelos, 2350 - 90035-003 - Porto Alegre, RS - Brazil. Received on $2 / 14 / 99$

Accepted on 6/9/99
IgA anti-bodies were increased in patients with heart disease as compared with control patients.

In 1992, Thom et al ${ }^{8}$ showed that patients with high levels of anti-Chlamydia pneumoniae IgG had twice the chance of having angiographically detectable coronary heart disease. In a study about prevalence ${ }^{9}$, carried out in a British community, a strong association between the antiChlamydia pneumoniae titers and the anti- $H$. pylori levels ( $\mathrm{IgG}>1 / 64)$ with ischemic heart disease diagnosed by electrocardiographic evidence of ischemia or infarction was demonstrated. This association remained significant after correction by a large range of potential confounding factors. This study also demonstrated that fibrinogen levels were higher in patients with elevated serology for both Chlamydia pneumoniae and for $H$. pylori, pointing to the possible mechanism involved.

Stronger evidence of the role that Chlamydia plays in ischemic heart disease has been provided by a study nested on the Helsinki Heart Study ${ }^{10}$, a randomized double blind clinical trial, primarily designed to check the efficacy of gemfibrozil in reducing the risk of ischemic heart disease. Analysis of serum collected from study participants 3 and 6 months prior to a coronary event showed that high serum levels of anti-Chlamydia pneumoniae antibodies constituted an independent risk factor for the development of a fatal or nonfatal coronary event, as compared with the control group who received the same treatment at the same time and place but had no infarcts ${ }^{10}$. The degree of association between the anti-Chlamydia pneumoniae antibodies and the risk for ischemic heart disease increased according to the serum levels of $\operatorname{IgA}$ and $\operatorname{IgG}$; this degree of association was statistically significant, even after correction for the traditional risk factors for ischemic heart disease. This study documented not only the association between the two variables but also the temporal relation between elevation of antibodies and coronary events.

In addition to these 3 population-based observational studies and the Helsinki Heart Study, a clinical trial, most of the published studies on serology of Chlamydia pneumoniae and atherosclerosis have found an odds ratio of at least 2 ; some studies have even reported that the higher the level of antibodies, the higher the risk. These studies were carried out in different populations, following different criteria, with different degrees of adjustments for confounding factors being, therefore, prone to bias. Consistency and directionality of the findings in a total of 2,700 patients 
studied suggest that a true association between Chlamydia pneumoniae and ischemic heart disease does exist ${ }^{11}$.

Helicobacter pylori - For Helicobacter pylori, available evidence suggests a milder relation to coronary atherosclerosis. A brief analysis of the controlled and prospective studies published so far suggests an odds ratio of approximately 1.5 , but without statistical significance. These data are derived from case control trials from large prospective studies, therefore reducing the selection bias, and assessing infection prior to the appearance of clinical manifestations. The sample size, however, is not large enough to detect, in a reliable manner, the association between Helicobacter pylori and coronary atherosclerosis ${ }^{11}$. None of the studies with more than 100 patients and 100 controls has revealed a significant association between Helicobacter pylori and ischemic heart disease ${ }^{11}$. Smaller and cross sectional studies, which detect stronger associations between Helicobacter pylori and coronary heart disease, are subject to innumerable not completely controlled variables, such as socioeconomic status, a factor known to be associated with infection by Helicobacter pylori and with ischemic heart disease.

Based on current evidence from the analysis of case control studies, one may say that a trend toward a positive association between Helicobacter pylori and ischemic heart disease exists; the results, however, may be due to biases not completely controlled and be, therefore, overestimated. In addition, independently from the degree of association occasionally found in these studies, they are, by definition, insufficient for assessing any causal association between infection by Helicobacter pylori and ischemic heart disease.

Cytomegalovirus - A series of case control studies on the relationship between cytomegalovirus and some forms of cardiovascular disease has already been published. Most of the studies report that patients with positive serology for cytomegalovirus have at least twice the chance of developing cardiovascular disease as compared with the controls whose serologies are negative, showing concordance and directionality in the findings. A major limitation of these studies, however, is that only two of them approach ischemic heart disease in its classical form ${ }^{11}$. The study that found the strongest association examined the relation between cytomegalovirus and restenosis after atherectomy ${ }^{12}$. In this study, 75 patients with symptomatic coronary heart disease, who had undergone atherectomy, were tested for the presence of anti-cytomegalovirus IgG to determine whether this constituted a risk factor for restenosis in 6 months, which was assessed through a new coronary angiography. Other studies examined different contexts, such as atherosclerosis after heart transplantation, or different anatomical regions with small samples and with little control for known confounding factors ${ }^{11}$. In the case of cytomegalovirus, even if this strong association is confirmed, it will not be possible to assure its role in the coronary atherosclerosis of native arteries.

\section{Evidence of the analysis of atherosclerotic plaques}

Chlamydia pneumoniae - This agent has already been identified through immunohistochemical analysis and polymerase chain reaction in coronary atheromas in autopsies of South African men ${ }^{13,14}$. More recently, the same team of researchers demonstrated Chlamydia pneumoniae in specimens of directional coronary atherectomy in 20 out of 38 specimens studied ${ }^{15}$. These studies were restricted to descriptions of the findings and did not report any association between the patients' serology for Chlamydia pneumoniae and the presence of the microorganism in the atheromatous plaques. The hypothesis that Chlamydia pneumoniae was more frequently found in patients with symptomatic ischemic heart disease than in those with other heart diseases was prospectively tested by Muhlestein et al ${ }^{16}$. They found evidence of Chlamydia pneumoniae in $79 \%$ of the atherosclerotic specimens studied and in $4 \%$ of the controls, which included individuals with healthy coronary arteries and posttransplantation coronary heart disease. According to a recently published meta-analysis that compiled results from 13 studies in this context, the chance (confidence interval of 95\%, 5-22) of finding local infection by Chlamydia pneumoniae in an atherosclerotic plaque is 10 times higher than in control specimens ${ }^{11}$. It should be noted, however, that even if a real and significant association occurs, it does not differentiate by itself whether the infection by Chlamydia pneumoniae causes the atheroma or whether the presence of the atheroma creates a favorable environment for the microorganism.

Helicobacter pylori-Studies are currently being carried out investigating whether Helicobacter pylori can be found in atherosclerotic lesions. In the only study that has been published so far, no DNA of Helicobacter pylori was found in abdominal aortic aneurysms in the 50 patients studied ${ }^{17}$.

Cytomegalovirus-Recentevidence from experimental studies has shown that some herpes viruses can alter the metabolism of cholesterol in smooth muscle cells, activate coagulation factors, and increase the expression of cytokines and adhesion molecules of the vascular wall ${ }^{18,19}$. In addition, some characteristics of atherosclerosis are similar to those of a benign neoplasia ${ }^{20}$, and herpes viruses may induce genomic transformation ${ }^{18}$. When atheromatous arteries were analyzed in regard to the presence of cytomegalovirus and compared with normal arteries, an analysis of 16 studies published found a slight positive association with atherosclerosis (odds ratio $=1.4$; confidence interval of $95 \%=1.0$ $-1.9)^{11}$. One difficulty in this context is that, even if the infectious agent starts the atherosclerotic process, it may not remain detectable. Therefre, the more sensitive the method employed, the greater the odds ratio found between cytomegalovirus and atherosclerosis. When the analysis of the plaques was performed through polymerase chain reaction, cytomegalovirus was detected in $75 \%$ of the atheromatous 
vessels and in $36 \%$ of the control specimens, generating an odds ratio of 2.5 (confidence interval of $95 \%=1.6-3.8)^{11}$. Even though the relation between cytomegalovirus and coronary heart disease is conventionally significant, it is not expressive, and does not provide convincing evidence regarding the relevance of the role of cytomegalovirus in atherosclerosis ${ }^{11}$.

Evidence from randomized clinical trials - Based on the biological plausibility of the association between infection and coronary atherosclerosis and on the observational findings existing so far, 3 small secondary prevention clinical trials with pharmacological intervention have been performed. Gupta et $\mathrm{al}^{21}$ observed the relation between antiChlamydia pneumoniae antibody levels and clinical outcome in patients surviving a myocardial infarction and demonstrated a statistically significant reduction in cardiovascular events after treatment with an antibiotic in a group of patients with high anti-Chlamydia pneumoniae antibody levels. The ROXIS pilot study ${ }^{22}$ randomized 200 patients with unstable angina or non-Q-wave infarction to receive, in addition to all the conventional treatment, the antibiotic roxithromycin or placebo ${ }^{22}$. These patients received the drug for 30 days after the acute event, and the combined outcome of cardiovascular death, myocardial infarction and severe recurrent ischemia was assessed at the end of this period. At the end of 31 days, a statistically significant reduction in the rate of occurrence of the 3 cardiovascular events was found. To better interpret the results, one might say that for each 100 patients treated with roxithromycin and conventional therapy, 7 significant cardiovascular events can be avoided. Follow-up studies, however, demonstrate that the effect fades after 3 to 6 months. These two experimental works were the first to test a therapeutical possibility based on the paradigm of infectious agents in the genesis or progression, or both, of ischemic heart disease, and have opened a broad new line of research.
Currently, a third clinical trial is being carried out contributing to the scarce data available relating Chlamydia pneumoniae to human atherosclerosis. The ACADEMIC study ${ }^{23}$ was designed with known stable ischemic patients, whose serology for Chlamydia pneumoniae was positive. Until now, an interin analysed with 1,800 patient-months did not show any difference in clinical outcomes between patients using azithromycin for a period of 3 months and patients receiving placebo. Even though studying different patients, with a lower risk but with positive serology, this trial provides data based on the largest number of patients already studied in this context. Until the study reaches its planned 2year follow-up, we only have incomplete information that in some ways diverges from the information from other trials.

\section{Conclusion}

Knowing the data from the different available studies, one can say that evidence relating infectious agents to the etiology of atherosclerosis does exist. One cannot yet, however, define whether these agents have the capacity to cause atherosclerosis, to promote progression of the lesions, or simply to be innocuous commensals of atherosclerotic plaques ${ }^{24}$. The first small trials addressing the role of Chlamydia pneumoniae in acute coronary syndromes provide incipient evidence that this bacterium may take part in the instability of the plaque and, therefore, in the genesis of myocardial infarction. On the other hand, other larger trials that are being carried out do not seem to provide positive results. Thus, it is not possible to choose a definitive management approach, either in regard to the role played by Chlamydia pneumoniae in ischemic heart disease or in regard to the role played by macrolide antibiotics in its treatment. In spite of all uncertainties, if antibiotics significantly reduce the incidence of coronary events, this will mark important progress in the treatment of ischemic heart disease.

\section{References}

1. Osler W. Diseases of the arteries. In: Osler W (ed) - Modern Medicine: Its Practice and Theory. Philadelphia: Lea \& Febiger, 1908: 429-47.

2. Ross R. The pathogenesis of atherosclerosis: an update. N Engl J Med 1986; 314: 488-500.

3. Fabricant CG, Fabricant J, Litrenta MM, Minick CR. Virus-induced atherosclerosis. J Exp Med 1978; 148: 335-40.

4. Peterson WL. Helicobacter pylori and peptic ulcer disease. N Engl J Med 1991; 324: 1043-8.

5. Vallance P,Collier J, Bhagat K. Infection, inflammation, and infarction: does acute endothelial dysfunction provide a link? Lancet 1997; 349: 1391-2.

6. Ribeiro JP, Clausell N. Em busca de novos paradigmas para o manejo da cardiopatia isquêmica. Arq Bras Cardiol 1997; 69: 1-12.

7. Saikku P, Leinonen M, Mattila K, et al. Serological evidence of an association of a novel Chlamydia, TWAR, with chronic coronary heart disease and acute myocardial infarction. Lancet 1988; ii: 983-6.

8. Thom DH, Grayston JT, Siscovick DS, Wang SP, Weiss NS, Daling JR. Association of prior infection with Chlamydia pneumoniae and angiographically demonstrated coronary artery disease. JAMA 1992; 268: 68-72.

9. Patel P, Mendall MA, Carrington D, et al. Association of Helicobacter pylori and Chlamydia pneumoniae infections with coronary heart disease and cardiovascular risk factors. Br Med J 1997; 311: 711-4.

10. Saikku P, Leinonen M, Tenkanen L, et al. Chronic Chlamydia pneumoniae infec- tion as a risk factor for coronary heart disease in the Helsinki Heart Study. Ann Intern Med 1992; 116: 273-8.

11. Danesh J, Collins R, Peto R. Chronic infections and coronary heart disease: is there a link? Lancet 1997; 350: 430-6.

12. Zhou YF, Leon MB, Waclawiw MA, et al. Association between prior cytomegalovirus infection and the risk of reestenosis after coronary atherectomy. N Engl J Med 1996; 335: 624-30.

13. Shor A, Kuo CC, Patton DL. Detection of Chlamydia pneumoniae in coronary fatty streaks and atheromatous plaques. S Afr Med J 1992; 82: 158-61.

14. Kuo CC, Shor A, Campbell LA, Fukushi H, Patton DL, Grayston JT. Demonstration of Chlamydia pneumoniae in atherosclerotic lesions of coronary arteries. J Infect Dis 1993; 167: 841-9.

15. Campbell LA, O'Brien ER, Cappuccio AL, Kuo CC, Patton DL, Grayston JT. Detection of Chlamydia pneumoniae TWAR in human coronary atherectomy tissues. J Infect Dis 1995; 172: 585-8.

16. Muhlestein JB, HammondEH, Carlquist JF, et al. Increased incidence of Chlamydia species within the coronary arteries of patients with symptomatic atherosclerotic versus other forms of cardiovascular disease. J Am Coll Cardiol 1996; 27: 1555-61.

17. Blasi F, Denti F, Erba M. Detection of Chlamydia pneumoniae but not Helicobacter pylori in atherosclerotic plaques of aortic aneurysms. J Clin Microbiol 1996; 34: 2766-9. 
18. Epstein SE, Speir E, Zhou YF, Guetta E, Leon MB, Finkel T. The role of infection in reestenosis and atherosclerosis: focus on cytomegalovirus. Lancet 1996; 348(supl. I): s13-17.

19. Kaner RJ, Hajjar DP. Viral activation of thrombo-atherosclerosis. In: Fuster V, Ross R, Topol EJ, eds - Atherosclerosis and Coronary Artery Disease. Philadelphia: Lippincott-Raven, 1996: 569-84.

20. Petrie BL, Adam E, Melnick JL. Association of herpesvirus/cytomegalovirus in fections with human atherosclerosis. Prog Med Virol 1988; 35: 21-42.

21. Gupta S, Leatham EW, Carrington D, Mendall MA, Kaski JC, Camm AJ.
Elevated Chlamydia pneumoniae antibodies, cardiovascular events, and azithromycin in

23. Anderson JL, Muhlestein JB, Carlquist J, et al. Randomized secondary prevention trial of azithromycin in patients with coronary artery disease and serological evidence for Chlamydia pneumoniae infection: the Azithromycin in Coronary Artery Disease: Elimination of Myocardial Infection with Chlamydia (ACADEMIC) study. Circulation 1999; 99: 1540-7.

24. Lip GYH, Beevers DG. Can we treat coronary artery disease with antibiotics? Lancet 1997; 350: 378-9.

\section{ERRATA}

Em relação ao artigo “Ablação com Radiofreqüência da Fibrilação Atrial Paroxística” publicado em Arquivos Brasileiros de Cardiologia 1999; 72: 693-700, no último parágrafo da discussão, onde é citado o artigo de Robbins e cols. (referência 24) devem ser suprimidas as palavras “...e colocação de stent nas ...”. Na realidade em ambos pacientes citados foi realizada apenas angioplastia das veias, sem colocação de stent. Portanto, a frase final deveria ser “...com necessidade de dilatação das quatro veias".

Mauricio Scanavacca

\section{ERRATA}

Regarding the paper "Radiofrequency Catheter Ablation in Patients with Atrial Fibrillation" published in Arquivos Brasileiros de Cardiologia 1999; 72: 693-700, in the last paragraph of the "Discussion", where is mentioned the article of Robbins et al ( $\left.n^{\circ} 24\right)$ the words "...stent positioning into the four veins ..." must be eliminated. As a matter of fact, in both patients was performed angioplasty of the veins without stenting. So, the final proposition ought to be "...requiring dilation of the four veins ...". 